This item was submitted to Loughborough's Research Repository by the author.

Items in Figshare are protected by copyright, with all rights reserved, unless otherwise indicated.

\title{
The conversational rollercoaster: conversation analysis and the public science of talk
}

PLEASE CITE THE PUBLISHED VERSION

https://doi.org/10.1177/1461445618754571

PUBLISHER

SAGE (@ The Authors)

VERSION

AM (Accepted Manuscript)

\section{PUBLISHER STATEMENT}

This work is made available according to the conditions of the Creative Commons Attribution-NonCommercialNoDerivatives 4.0 International (CC BY-NC-ND 4.0) licence. Full details of this licence are available at: https://creativecommons.org/licenses/by-nc-nd/4.0/

\section{LICENCE}

CC BY-NC-ND 4.0

\section{REPOSITORY RECORD}

Albert, Saul, Charlotte Albury, Marc Alexander, Toby Harris, Emily Hofstetter, Edward Holmes, and Elizabeth Stokoe. 2019. "The Conversational Rollercoaster: Conversation Analysis and the Public Science of Talk". figshare. https://hdl.handle.net/2134/26429. 


\section{The conversational rollercoaster ${ }^{1}$}

Conversation analysis and the public science of talk

Saul Albert ${ }^{1,4}$; Charlotte Albury ${ }^{2}$; Marc Alexander ${ }^{3}$; Toby Harris ${ }^{4}$; Emily Hofstetter ${ }^{5}$; Edward Holmes ${ }^{6}$; Elizabeth Stokoe ${ }^{7}$

1. Tufts University; 2. University of Oxford; 3, 5, 7. Loughborough University;

4. Queen Mary University of London; 6. University of York

In press, Discourse Studies, 2018, 20(3)

\footnotetext{
${ }^{1}$ Authors are listed alphabetically. Saul Albert drafted, coordinated, and co-edited the paper with Elizabeth Stokoe, Charlotte Albury and Emily Hofstetter contributed descriptions of the Rollercoaster components and how the exhibit functioned, Marc Alexander re-transcribed and analyzed the data segments with Saul Albert, Toby Harris contributed technical descriptions of the exhibit, Edward J. B. Holmes contributed the sections 'CA's Public Ethos' and 'CA in public life', and Elizabeth Stokoe wrote the introduction and conclusion.
} 


\title{
The conversational rollercoaster ${ }^{2}$
}

\section{Conversation analysis and the public science of talk}

\author{
Saul Albert ${ }^{1,4}$; Charlotte Albury ${ }^{2}$; Marc Alexander ${ }^{3}$; Toby Harris ${ }^{4}$; Emily Hofstetter ${ }^{5}$; \\ Edward Holmes ${ }^{6}$; Elizabeth Stokoe ${ }^{7}$
}

1. Tufts University; 2. University of Oxford; 3, 5, 7. Loughborough University;

4. Queen Mary University of London; 6. University of York

\section{Abstract}

How does talk work, and can we engage the public in a dialogue about the scientific study of talk? This paper presents a history, critical evaluation and empirical illustration of the public science of talk. We chart the public ethos of conversation analysis that treats talk as an inherently public phenomenon, and its transcribed recordings as public data. We examine the inherent contradictions that conversation analysis is simultaneously obscure yet highly cited; it studies an object that people understand intuitively, yet routinely produces counter-intuitive findings about talk. We describe a novel methodology for engaging the public in a science exhibition event, and show how our 'conversational rollercoaster' - involving live recording, transcription and public-led analysis - addressed the challenge of demonstrating how talk can become an informative object of scientific research. We conclude by encouraging researchers not only to engage in a public dialogue, but also to find ways to actively engage people in taking a scientific approach to talk as a pervasive, structural feature of their everyday lives.

\section{Introduction}

Rather than communicating science to address a perceived 'deficit' of public understanding, scientists are increasingly expected to engage the public in forms of dialogue that enhance the 'impact' of their research (Terama, Smallman, Lock, Johnson \& Austwick, 2016). However, the aims, methods, and appropriate measures of impact for this kind of public dialogue remain largely unclear (Stilgoe, Lock \& Wilsdon, 2014). For social interaction researchers, it can seem challenging enough to engage in dialogue with other academics - let alone with the public — when their object of scientific study is dialogue itself (Heritage, 2008: 301).

Prominence is often accorded to mediagenic research in the psychology of social behavior (Ranehill et. al, 2015), and 'communication skills' that tends to theorize about fixed 'rules' for interaction (Turner, 2001), rather than deal with the apparent messiness of natural talk (Stokoe, 2011). We argue that there is clearly a deficit that needs to be addressed, and scientists need to find new ways to engage partners in dialogue both within and beyond academia to promote greater awareness of rigorous empirical research into human interaction.

This article aims to open a discussion about the challenges, approaches, and appropriate measures of success for his kind of public dialogue. We present a case study featuring a novel approach to engaging visitors in discussing and analyzing talk in a science exhibition context.

\footnotetext{
2 Authors are listed alphabetically. Saul Albert drafted, coordinated, and co-edited the paper with Elizabeth Stokoe, Charlotte Albury and Emily Hofstetter contributed descriptions of the Rollercoaster components and how the exhibit functioned, Marc Alexander re-transcribed and analyzed the data segments with Saul Albert, Toby Harris contributed technical descriptions of the exhibit, Edward J. B. Holmes contributed the sections 'CA's Public Ethos' and 'CA in public life', and Elizabeth Stokoe wrote the introduction and conclusion.
} 
We start by exploring various approaches to public engagement in relation to conversation analysis (CA), ${ }^{3}$ and the challenges of showing how talk can become an informative object of scientific research in the first place. We show how the superficial ordinariness of conversation conceals the systematic structure of social interaction from scientists and participants in conversation alike, and how the 'public ethos' and methods of CA have been shaped by the need to solve this problem. We then focus on a case study of an exhibit at a science festival: 'The conversational rollercoaster', in which CA's methodological tools are adapted to involve exhibition visitors in doing research and producing their own findings live. We argue that involving members of the public in generating novel empirical findings can engage them in a dialogue with scientists, but also, crucially, with scientific materials and methods. We show how their 'public science' findings can be viable for use in future research, and that they therefore constitute practical, endogenous evidence of 'impact'. Finally, we propose that interaction researchers from across disciplines and methods could use these strategies to engage people in dialogue through a 'public science of talk' that focusses on revealing the natural structure of interaction. We encourage researchers to engage in public dialogue, but also to find new ways to engage people in using scientific methods and approaches to the study of talk as a pervasive structural feature of their everyday lives.

\section{Could conversation analysis be a public science?}

Conversation analysis has a fifty-year history of studying how what might be glossed as 'interpersonal communication' works. Research on how people take and design turns at talk is amongst the most cited in academia. An article in Nature entitled 'The top 100 papers', listing the most-cited research of all time, identified mostly papers in the 'hard' sciences, with citations ranging from $305 \mathrm{~K}$ to $12.2 \mathrm{~K}$ at the time of publication in 2014 (Van Noorden, Maher and Nuzzo, 2014). CA's foundational paper on turn-taking in conversation by Sacks, Schegloff and Jefferson (1974) currently has $13.8 \mathrm{~K}$ citations, and the authors have $150 \mathrm{~K}$ cites collectively. For a relatively unknown discipline, even within communication studies, CA's academic impact is massive. Despite focusing on the fundamentals of human communication and having such a large impact on academia, there has been little crossover from CA's empirical work into the realms of popular science, although its relevance for non-academics is clear. Popular psychology has taught us to think and talk about life and behavior in terms of gender, culture, personality, and other abstract variables. We tend to think we are individuals who behave according to our intentions, in idiosyncratic ways. However, conversation analytic research shows that people are pushed and pulled around by words, phrases, intonation - by talk - far more than they are necessarily aware. More recently CA has undergone a dramatic change in visibility and impact and, as this paper shows, the scientific study of dialogue can engage the public in multiple ways, from simple interest and entertainment, to working with users in co-designed communication research projects with profound implications for how we understand and use talk. Each scientific approach to discourse has its own specific origins, but here we chart the development of CA as a 'public science of talk', and show how its materials and methods lend themselves to engaging people in CA's research processes as well as (if not more than) its published scientific findings.

\footnotetext{
3 The exhibit we present here as a case study is based on CA, but the exhibit described here could easily be adapted for science engagement in other methodological approaches to discourse, interaction and communication.
} 
CA's obscurity within communication research and the simplicity of engaging the public in doing CA may result from talk (a naturally familiar phenomenon) being its object of interest. When we try to understand something like talk scientifically, it is not the same as trying to understand something like a black hole or some clearly demarcated scientific phenomena. Talk, as a phenomenon of social life, is there to be understood. It is designed by humans for humans to get every facet of life accomplished, including the analysis of black holes or other scientific work (Schegloff, 2006: 90). We build, maintain and end our personal and professional relationships through talk. We buy and sell. We get and give help. We are excited, persuaded, irritated, embarrassed, and consoled in response to things others say to us. Talk is the tool we use to do all of these things. It is also our resource for fixing things that go wrong. When we describe some aspect of our conversations as 'communication breakdown', we are probably referring to feeling trapped in a conversation, or that we are struggling to get heard, or as though we are on the back foot. Conversation analytic research studies these topics via the forensic scrutiny of recorded, naturally occurring social interaction. While black holes may be the focus of legitimate scientific interest, they do not exist in order to be understood by humans. Talk, on the other hand, exists only to be understood by humans. In that sense, research about the science of talk should be easy to translate for non-academic audiences; the conceptual gap between the audience and the phenomenon is small (Stokoe, 2017). On the other hand, it can also be a challenge to convince people (especially academics) that we need a scientific approach to the study of something thing that seems, on the surface, so easy to understand. Can we really gain anything by analysing something that we 'just do'? Fifty years of conversation analytic research and some of the recent developments in its public profile reported in this article shows that the answer is 'yes'.

Talk is a particularly useful phenomenon for empirical study because everyday interactional practices such as turn-taking are intricately well-coordinated (Sacks, Schegloff \& Jefferson, 1974). Although Chomsky (1964, pp. 200-201) once described conversation as a 'deficient', disorderly phenomenon, conversation analysts have shown it is in fact strikingly well organized. Analysing talk in the wild - that is, in 'ordinary conversation' (Schegloff, 1989: 143) - shows us the power that talk has to shape our daily lives, despite the fact that we remain quite unaware of how systematic our talk is, and how the different words we use lead towards different conversational outcomes. So, while we are all highly skilled at talking, listening and interacting, we do not seem to be good at introspecting about what might have gone wrong in an encounter, or what went right. Think about the last time you went on a rollercoaster. You might have seen - even if you did not purchase it - the snapshot of yourself as you zoomed down the steepest incline. You probably did not realize what your face was doing at that precise moment. Similarly, we are not capable of recalling and reproducing - with the exact words, the exact intonation, and the exact facial expressionwhat we said at 33 minutes and 4 seconds into a particular conversation. Studying talk scientifically allows us to freeze-frame that moment and scrutinize it to see which interactional moves 'worked', which ones did not, and how people collaborated to achieve specific interactional outcomes. This motif of the snapshot after the rollercoaster ride provided the metaphor a team of analysts used to involve members of the public in trying CA for themselves during the New Scientist Live event from the 22nd-25th September at the ExCel conference centre in London. 'The Conversational Rollercoaster' (CR) invited people to analyse a spontaneous conversation between visitors live. The unexpected success of this exhibit raised the question of why there are no well-established methods for exhibiting CA at science fairs or public demonstrations, and whether there are specific barriers to or opportunities for engaging the public with $\mathrm{CA}$. This paper sets out to address these questions 
by exploring how CA has developed a methodologically specific public ethos, and to trace the brief history of CA's public demonstrations and engagements.

\section{CA's public ethos}

CA has only recently begun to approach the 'public turn' in the social sciences (e.g. Burawoy, 2004), and the closest CA research usually comes to achieving this disciplinary engagement with a notional 'public' is through research in 'applied' as opposed to 'pure' CA (Richards \& Seedhouse, 2005; Antaki, 2011). However, this relative lack of explicitly public engagement is surprising because CA - as an 'enterprise' (Schegloff, 1992: xx), as a 'method of inquiry' (Schegloff, Koshik, Jacoby \& Olsher, 2002: 4) and as an 'analytic mentality' (Schenkein, 1978: 58; Heap, 1990) - is on based a set of theoretical commitments, empirical practices, and analytic foci that can be seen to constitute a kind of 'public ethos'. Given CA's inherently public (as in publicly observable) objects of study and methods of inquiry, the apparent lack of established approaches to forms of 'public CA' is somewhat ironic. Here we argue that CA is naturally suited to engagement with non-scientists by tracing three key manifestations of CA's public ethos, starting with its central object of study: conversation.

\section{The inherently public phenomenon of talk}

At various points in his posthumously published Lectures on Conversation, CA's founder Harvey Sacks (1992 [1964-1972]) describes setting out to start a new scientific field before developing CA's focus on talk as it is used in interaction (often termed 'talk-in-interaction'). Schegloff (1992) explains that Sacks' project was much further-reaching. He wanted to develop a science of 'how ordinary activities get done methodically and reproducibly, and the organization of commonsense theorizing and conduct which was relevant to those enterprises' (ibid.: xvii). Sacks later focused on the analysis of recorded conversations, although he had not 'theoretically projected' (ibid.) adopting this focus, for which there were few antecedents in the social sciences. ${ }^{4}$ Rather, as Sacks (1992) makes clear, talk-in-interaction was an incidental choice of material, selected because it happened to be useful for the type of empirical investigation of social interaction he envisioned. One reason conversation seemed especially useful as an object of study was the possibility it afforded for the public verification of CA's empirical research findings.

'It wasn't from any large interest in language, or from some theoretical formulation of what should be studied, but simply by virtue of that; I could get my hands on it, and I could study it again and again. And also, consequentially, others could look at what I had studied, and make of it what they could, if they wanted to be able to disagree with me.' (Sacks, 1992 [1967]: 622)

Sacks considered this kind of public verification integral to the scientific practice of sociology (although, see Lynch and Bogen, 1994), and often returned to this theme in his early programmatic statements about the nascent discipline that would later be named CA.

'I figured that sociology couldn't be an actual science unless it was able to handle the details of actual events; handle them formally, and in the first instance be informative about them in the ways that primitive sciences tend to be informative. That is to say, you 
could tell your mother something you found out, and she could go and see that it was so.' (Sacks, 1992 [1967]: 621-622)

'I'm trying to develop a sociology where the reader has as much information as the author, and can reproduce the analysis. If you ever read biological paper it will say for example, 'I used such-and-such which I bought at Joe's drugstore.' And they tell you just what they do, and you can pick it up and see whether it holds. You can re-do the observations. Here I'm showing my materials and others can analyze them as well [...]' (Sacks, 1992 [1964-1965]: 27)

Talk-in-interaction is inherently conducted as a public activity (Goffman, 1963), and analysts focus on the issues participants themselves make publicly relevant via talk. Analysts can track how people publicly inspect and correct their own talk (e.g., "that woman- you knowthe one with the curly hair"; "I think that- well, I KNOW that...") and reveal the participants' own analyses of unfolding interactions (e.g., "What do you mean, you're sorry!"; "your silence speaks volumes!"). Sacks' commitment to public verification and talk as the core material and domain of CA therefore exemplifies CA's public ethos. Since participants in the interaction share 'independent access to the data being described' with analysts and readers of conversation analytic transcripts of talk (Schegloff, 1987a: 105, fn. 5), all parties can-if they are so inclined - conduct their own forms of analysis.

\section{CA's public data}

CA's approach to transcribing talk also manifests its public ethos by providing opportunities for various forms of public verification. The Jeffersonian orthographic system (Jefferson, 2004) is used to annotate and emphasize features of talk that are demonstrably relevant to the participants in a systematic and analytically informed way. As Hepburn and Bolden (2013: 57) write, the system allows for the transcription of 'not only what is said but also details of how something is said'. The International Phonetic Alphabet (International Phonetics Association, 1999) may provide greater accuracy and apparent objectivity; however, Jeffersonian transcription emphasizes details such as precisely when and how some utterance is produced, and focuses on sequential phenomena such as silences, overlaps and disfluencies that show how participants treat these as consequential events for the purposes of their current interaction. Jefferson's system has since been modified to enable transcription of a wide range of interactional practices including non-vocal activities (e.g. Goodwin, 1981; Atkinson, 1984; Schegloff, 1984; Rossano 2012; Mondada 2014). CA's transcription system therefore provides a balance of flexible and standardized methods for representing interaction as a public activity, while highlighting the basis of the analytical claims it is used to illustrate. Jefferson's transcription system exemplifies CA's public ethos in the way it constitutes and reconstitutes talk-in-interaction (Kitzinger, 1998) as an inherently public object of inquiry. ${ }^{5}$

\section{The data session}

A further example of how CA's public ethos is embedded in its research methods is the 'data session' where analysts informally review transcripts, analyses, and original recordings

\footnotetext{
5 The public availability of transcribed materials also has a kind of 'social life' as secondary data. Datasets transcribed for the purposes of CA research circulate amongst peers and can become 'classic CA corpora' (Kitzinger, 2005: 225), subjected to repeated analysis in a wide range of CA research in both ordinary and institutional settings (e.g. Jefferson, 1988; Curl and Drew, 2008; Heritage, 2012). These transcripts not only render the details of talk-in-interaction publicly, but are also rendered public through use as secondary data.
} 
together at an early stage in the research process (ten Have, 1999: 124). Researchers prepare a few segments of recorded and transcribed data and can outline their specific analytic interests for the group, or open the session for 'unmotivated looking' (see Schegloff, 1999: 577-578) and inductive analyses generated on the fly. Data sessions address a wide range of phenomena (Schegloff, 1999: 578) and are open to unanticipated discoveries (Schegloff, 1996). They perform both pedagogic (Harris, Theobald, Danby, Reynolds and Rintel, 2012) and communal functions (Bushnell, 2012), and function as a public demonstration of CA-inaction. Of course, the 'public' in this case is usually restricted to members of a specific academic field (Bourdieu, 1988) for whom the data session represents 'routine intramural work' (Antaki, Biazzi, Nissen and Wagner, 2008: 5). However, novices and practitioners from other areas of social or institutional life are often inducted into CA through the data session. For example, when examining recordings of doctor/patient interactions, it is common to involve someone with medical knowledge who can discuss clinical issues that may not be invoked explicitly within the recorded talk, but which may have a bearing on the interaction and its possible consequences for the participants in the social setting in question.

When analyzing interaction, Schegloff (1999: 579) notes the danger of over-theorizing and projecting the assumptions of analysts - and their 'communities of relevance' onto the interactional conduct of participants. Both expert analysts and lay people may reach for generic theoretical explanations of communicative behaviors (e.g. that it's about power) or culturally salient variables (e.g. it's because she's a woman) or psychological motives (e.g. what he really thinks). Such intuitive assumptions often underpin popular science claims about, for example, differences in the frequency of 'interruptions' by men or women, and these claims persist despite evidence to the contrary from empirical studies (Drew, 2009). To counteract this tendency to theorize about the interpretative relevance of communication acts, the main purpose of the data session is to focus on issues of 'interactional relevance'. 6 When pointing out something of interactional relevance within the data session, analysts must be able to demonstrate how something like power or gender is observably consequential for those involved in the action underway (e.g. "ladies first!"). The data session provides a check on theoretical speculation by inviting analysts to proffer candidate analyses and have them subjected to informal public peer review at an early stage. The CA data session, then, operationalizes interaction itself to achieve a compromise between objective assessment on the one hand, and speculative involvement with participants' apparent motivations and intentions on the other. The analyst's interactional abilities function as an inductive measure of what can be shown to be relevant for the participants themselves in relation to the data available. This process mitigates otherwise intractable 'problems of relevance' (Schütz, 1962 pp. 99-199) for interaction research in a practical and publicly accountable way.

The conversational rollercoaster used the gathering and transcribing of data and the data session as a scaffold for engaging visitors. The CR mirrored the structure of the data session as a site of analyzing and re-analyzing data in a group composed of exhibition visitors and professional analysts. The accessible nature of CA's transcriptions and the inherently accessible phenomenon of talk provided a focus of inquiry with many opportunities for engaging exhibition visitors in doing CA in public. We have argued that CA's public ethos,

\footnotetext{
6 'Relevance', here, is not some pre-specified, static, or objective set of criteria for testing analytical or scientific claims, nor does relevance in this context refer to whatever participants might say-if asked-they had experienced as relevant in the situation (Sacks, 1992 [1966]: 470). People are usually unable to recall the precise timing of turns at talk, or the onset or offset of overlap at the level of detail required for CA study. Rather, Sacks' intended CA to treat talk as zoology treats animal behavior (Sacks, 1992 [1964-1965]: 27) where 'interactional relevance' is consequential for-but usually orthogonal to-participants' avowed intentions.
} 
its publicly verifiable data and its methods could inspire public exhibits of CA, but it could also inform how researchers engage with various aspects of public life: through its approach to topical issues in public life, and through more direct interventions as 'applied CA'.

\section{CA in public life}

CA studies the inherently public aspects of social life. Whatever may or may not be going on in our minds, brains, memories, etc., we live our social lives in the public interactional realm. For example, if someone says "I love you", we have nothing to check our assumptions against except their actions up to and including the declaration itself. This inherently public nature of talk lends itself to analysis via CA's publicly verifiable practices of transcription, and its publicly accountable approach to data analysis. However, the ways CA has entered public life have, until recently, emphasized how useful it can be when applied, rather than the inherent 'publicness' of its methods and practices. This may be because, taken at face value, CA's basic foci and (ostensibly) microanalytic research questions (Schegloff, 1987b: 209) such as 'how do people take turns-at-talk?'; 'How are turns constructed and repaired?'; and, 'How do turns form sequences?' can seem almost trivial (e.g. Coser 1975: 698; cf. Heritage, 2008: 301). Nonetheless, where CA has addressed wider social, societal and sociological topics (e.g. Heritage, 1984: Schegloff, 1987b; Kitzinger, 2000; Clayman, 2002; Stokoe \& Edwards, 2007; Heritage, 2008), it has found that self and society are instantiated and coproduced in public through these minutiae of interactional behavior. Seen from up close, these micro-structures of talk are far more stable and tractable than ostensibly significant phenomena. As Schegloff (2006: 70) points out about the fall of the Sovient Union:

'[w]hen the most powerful macrostructures of society fail and crumble (as, e.g., after the demise of the communist regimes in Eastern Europe), the social structure that is left is interaction, in a largely unaffected state.'

The 'particularizing objective' (Heritage, 2003: 6) of CA is to analyze minute and often single instances of talk (Schegloff, 1987a) to show how these 'private problems' such as who gets to take the next turn are co-produced as 'public issues' (c.f. Mills, 1959) in specific situations. Applied CA asks how individuals demonstrate the relevance of sexuality (Kitzinger, 2005), social class (Holmes, in preparation), gender (Speer and Stokoe, 2011), or race (Whitehead, 2009) through habitual patterns of interaction in everyday life. CA's public ethos is reinforced by the way it focuses on the seen-but-unnoticed systems of identity and social division by revealing the empirical, verifiable, and often mundane detail of how these systems are manifested, encountered and sustained in and through talk-in-interaction (Stokoe, 2013).

\section{Applied CA}

More recent applications of CA to intervene in public or institutional life by, for example, identifying problems in services or improving training methods (Drew, Antaki, 2011; Stokoe, 2011), show how CA's public ethos, data and methods are especially useful for identifying problems and solutions that correspond to participants' endogenous issues and approaches.

'[CA] is applied to an interactional problem which pre-existed the analyst's arrival; it has the strong implication that a solution will be identified via the analysis of the sequential organization of talk; and it is undertaken collaboratively, achieved with people in the local scene.' (Antaki, 2011: 8) 
CA's assumption is that any ostensible problems and their interactional solutions must already be evident — even if seen but unnoticed — in the public record of social interaction. For example, in primary care consultations, Heritage, Robinson, Elliott, Beckett, and Wilkes (2007) used CA to improve the institutional problem of patients not stating unmet medical concerns. The authors explored why patients routinely go to the doctor with an average of three medical concerns, but tend to leave having discussed only one. Heritage et al. (2007) explored features of doctors' turn designs when eliciting medical concerns and found that if

doctors asked patients if there was 'SOMEthing else' to discuss, patients were far more likely to present additional concerns than if doctors asked if there was 'ANYthing else'. Similar CA 'interventions' are increasingly useful in, for example, dealing with 'troublesome' client questions (Wilkinson, 2011), improving response rates in telephone interviews (Maynard, Schaeffer and Freese, 2011), and reducing patient challenges in GP surgeries (Sikveland, Stokoe \& Symonds, 2016). These interventions apply CA to areas of public life, where the 'public' is made up of healthcare, service and administrative professionals.

\section{Public demonstrations of CA}

CA has rarely been demonstrated to a 'general public' as in the exhibit we describe below. One important precursor, however, was Atkinson's (1984) public experiment demonstrating how politicians elicit applause during speeches. Alongside the publication of his research on this topic (cf. Heritage and Greatbatch, 1986), Atkinson also staged a 'public test' of his findings at the 1984 Social Democratic Party (SDP) conference (Atkinson, 1984: xix). Having written a speech based on his observations of applause-elicitation, Atkinson coached a non-platform speaker, Ann Brennan, to deliver the speech, with dramatic results:

'Mrs Brennan was applauded so much that she had only got two-third of the way through her speech when the chair intervened to say she had run out time - at which point she became the only non-platform speaker to win a standing ovation at that year's SDP conference.' (Atkinson, 1984: xix)

Following the speech, Atkinson announced that this had been an experiment, and the Granada Television crew who were recording the event for a documentary (Atkinson (2010 [1985]) recorded interviews gauging the reactions of other SDP delegates. This event engaged and constituted various 'publics' in a live, naturalistic experiment, with the intention of exploring the existing interactional practices of political speech-makers and the responsive actions of applauding audiences (Atkinson, 1984: xvii-xviii). This bringing together of various publics makes Atkinson's experiment a close precursor to the demonstration reported in this paper: the 'Conversation Rollercoaster' (CR), set out to engage and constitute one 'public' by facilitating a live, spontaneous group conversation, while involving another 'public' (possibly including some of the same people) in using CA's data and methods to analyze the first public's live interaction. Whereas Atkinson's experiment involved people in CA by implicating them in the outcomes (e.g. a standing ovation) before revealing the apparatus through which that result was achieved, the $\mathrm{CR}$ attempted the opposite: putting the apparatus and procedure of $\mathrm{CA}$ up-front by revealing the activity of people conducting $\mathrm{CA}$ in public. 


\section{The Conversational Rollercoaster}

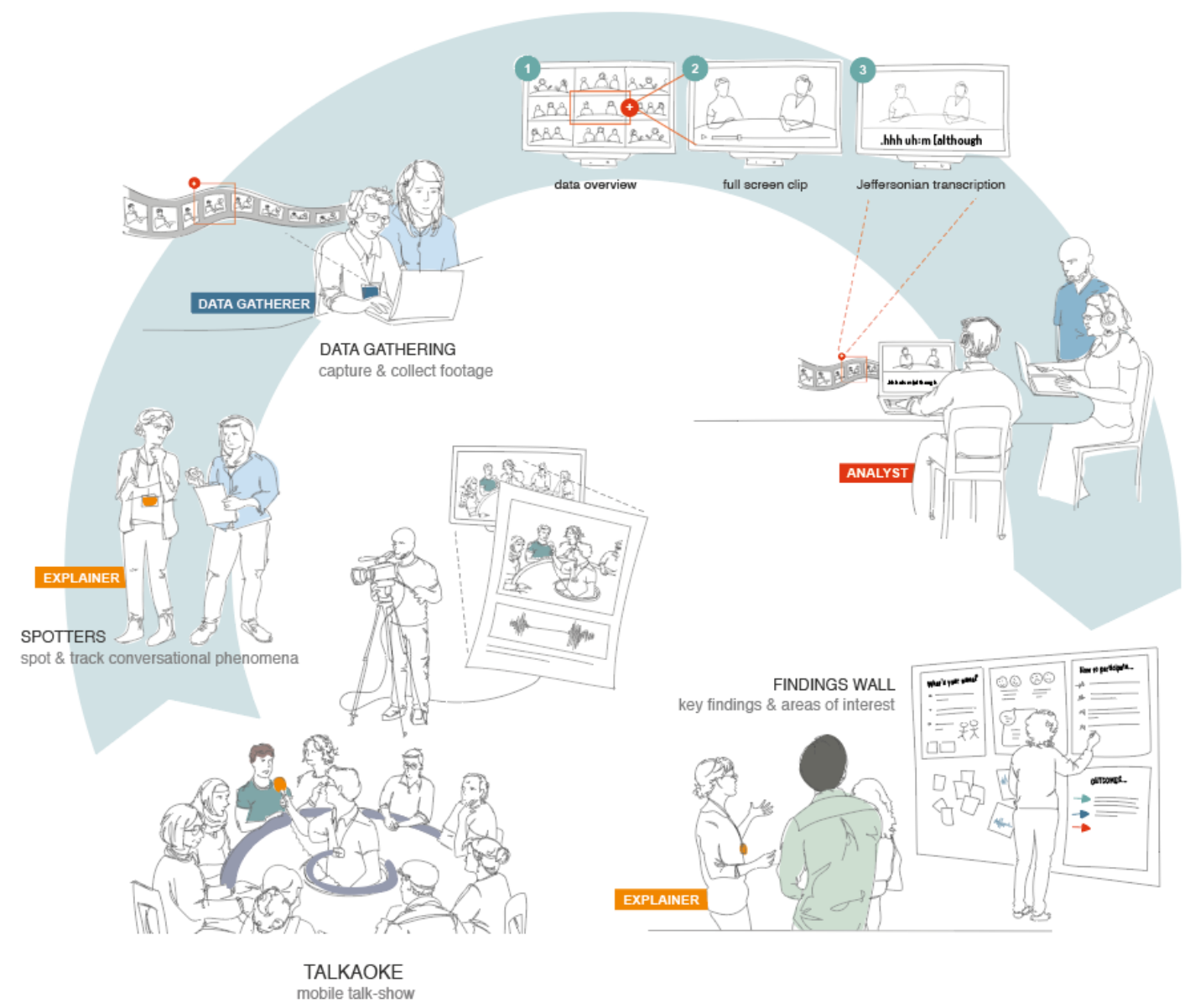

Figure 1: A visual overview of the Conversational Rollercoaster exhibit.

The exhibit was one of around 50 exhibition stands at New Scientist Live. The CR occupied a 5 square metre area with access from the aisles between stands on three sides, set against a partition wall. The area was marked out by a square of grey carpet, bounded by the purple of the aisles. The centrepiece of the exhibit was 'Talkaoke' (see Figure 1a), a mobile talk-show based around a doughnut-shaped table where the Talkaoke host sits in the middle of the doughnut on a swivel chair wearing a headset microphone, ready to spin around and offer a handheld microphone to any participant or bystander around the edge. Talkaoke was positioned so that visitors to the CR could approach and sit down from any side, and the Talkaoke table's built-in speakers and amplification system made sure that the conversation around the table could be heard from a distance. Since Talkaoke is an established participatory event format ${ }^{7}$ with many trained 'hosts', it provided the CR with a reliable method for stimulating conversation. A static webcam was positioned off to the side of the $\mathrm{CR}$, with a second hand-held video camera providing close-up shots. These video feeds were mixed for live video projection onto the partition wall, as well as for web streaming. The analysis component of the CR comprised an ad-hoc workspace flanked by three large video

\footnotetext{
${ }^{7}$ See http://talkaoke.com.
} 
displays. A team of professional analysts set up a series of adjacent tables performing conversation analytic tasks in public, often demonstrating their work and discussing it with attendees. For example, a group of analysts would intercept curious passers-by to explain what was going on, and to help those interested to spot phenomena of analytic interest as they occurred. These 'spotters' would then inform the 'data gatherers' at the video mixing workstation about which moments to capture. They would capture video clips and display them on the large video screens, while explaining this process to visitors and passing clips to the 'transcribers'. The analyst at the transcription station laptop would then transcribe talk from video clips while explaining Jeffersonian transcription to visitors and inviting them to try it. Other analysts worked as 'explainers' and conducted a live, ongoing public data session to develop ad-hoc findings that were written up on temporary 'findings wall' made from temporary whiteboard material stuck onto the partition wall behind the Talkaoke table. The $\mathrm{CR}$ functioned as a kind of public production line for CA, demonstrating and inviting people to try CA methods, and to engage in producing and analyzing live conversational data.

\section{Evaluating a public exhibit of CA}

The Conversational Rollercoaster exhibit aimed to engage visitors in a public dialogue using CA's public ethos and methods to get them involved in analyzing dialogue for themselves. However, conventional approaches to evaluating the success of science exhibits such as surveys or dwell-time (Heath, vom Lehn and Osbourne, 2001) would probably provide an unreliable measure of the CR's 'impact', since this would involve asking participants to reflect on and evaluate the organization of a process which has been structured by the activities of the participants themselves (Atkinson and Heritage, 1984: 6). Rather, we suggest that a more appropriate evaluation of the CR should involve the same detailed, schematic descriptions and data analysis as the conversation analytic methods the CR seeks to promote. Evidence of the CR's success, then, is constituted by visitors' practical displays of understanding. The quality of their findings can provide an endogenous measure that is more in keeping with CA's methods, and with a more profound form of dialogue in public science. The descriptions below detail the procedures and methods of each component of the CR, and help calibrate the metric for success with which we can evaluate visitors' empirical findings.

\section{The public phenomenon of Talkaoke}

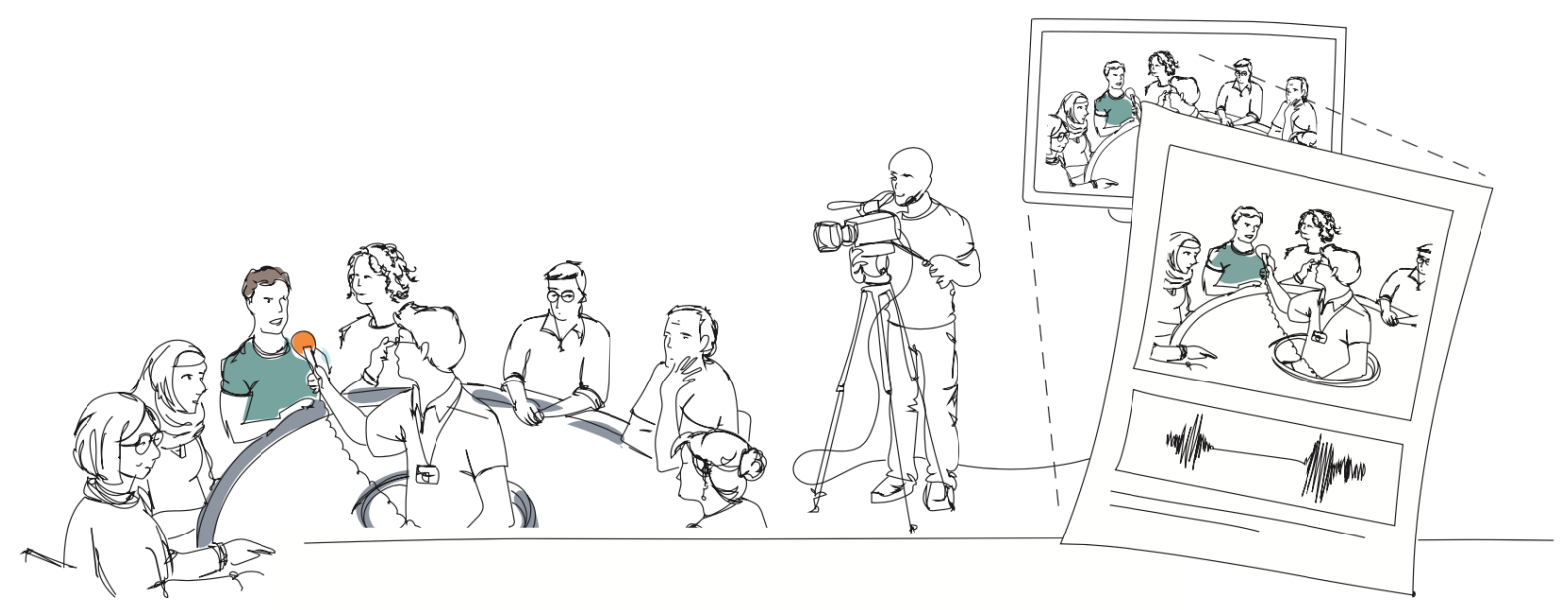

Figure 2: The Talkaoke table in action while video recordings are turned into instant 'snapshots'. 
The clearest difference between the $\mathrm{CR}$ and how conversation analysts usually use naturally occurring data was that the CR required data to be generated in the first place. Passers-by could join in with Talkaoke (see Figure 2), then learn to analyze the conversations arising from it. This provided a continuous stream of conversation and a central focus for the exhibition space. The Talkaoke table is visually arresting, and the host encourages people to sit and engage in conversation. At the CR, Topics were raised, sustained or changed by visitors to the exhibition, with the host occasionally summarizing for the sake of new visitors as they joined the table. Apart from the physical layout, there were no predetermined constraints on who could sit down, or on the length or direction of discussions, so a diverse set of visitors including scientists, exhibitors, school children, students, teachers, retirees, and one talking robot participated in Talkaoke, generating conversational data incidentally ${ }^{8}$. The dual function of Talkaoke as a talk-show and as a data source may have not been immediately apparent to these participants, so an additional stage was required to present Talkaoke to the participants as data for analysis. This was the purpose of the 'Conversational Rollercoaster' metaphor. As each person sat down at the Talkaoke table, the 'data gatherers' (see Figure 3) would take a screenshot of the participant's face from the live video feed with a graphic of a waveform representing their voice into a printed 'snapshot' of them talking (see Figure 10). These snapshots functioned much like the instant photos people can buy of themselves following a ride on a rollercoaster: it aimed to explain the switch from participating in the flow of conversation to analyzing it as video data. Once a participant had left the Talkaoke table, analysts would offer them a copy of their snapshot and explain that they could now take part in the CR. This also demonstrated how specific moments in talk may be worthy of analytic attention, and drew participants into the CR's production line of analytic activities.

Conversation analysis typically works with naturalistic recordings of conversation (Potter, 2000) rather than interviews or experimentally controlled and manipulated dialogues. While Talkaoke is not a 'natural' conversation in the sense of being 'equivalent to everyday talk between friends', it was natural in that participants organized their behavior spontaneously. As people interact during Talkaoke and the CR, they construct and orient to the perceived and assumed rules of engagement, and so demonstrate their understanding of how interaction at this kind of talk-show 'should' work. CR participants - most of whom had just participated in Talkaoke - could draw on this just-prior experience to inform their attempts at doing conversation analysis, along with prior understanding and experience of natural conversation. The endogenous structure of Talkaoke is as observable to analysts watching video clips of Talkaoke as it is for participants, and Talkaoke also rendered certain aspects of conversation more accessible to people trying conversation analysis for the first time. For example, turntaking at Talkaoke is more easily observable than in everyday talk because speakers must use a microphone, so observers can track how each person achieves being selected to speak next. Similarly, when joining Talkaoke, passers-by would visibly slow or stop as they walked past the spectacle, and would then become targets for invitations to join by the Talkaoke host. Visitors would use different strategies to avoid being joining: holding up a palm, smiling, shaking their heads or looking down or away as they speed up and away from the table. As a kind of caricature of an everyday conversation, Talkaoke provided many very clear phenomena for inspection, along with clearer audio and video recordings than is often the case in CA field recordings. The CR drew people in as analysts by using Talkaoke to emphasize these inherently public phenomena and the ways they are used in conversation.

\footnotetext{
${ }^{8}$ The analysts did not try to manipulate or steer the conversation, although the analysts were occasionally called upon by the host to report their findings to whoever was at the Talkaoke several times during the day. However, these findings typically became a tangent for the ongoing conversation and did not alter the structure of the conversation in any lasting way.
} 


\section{Building empirical materials in public}

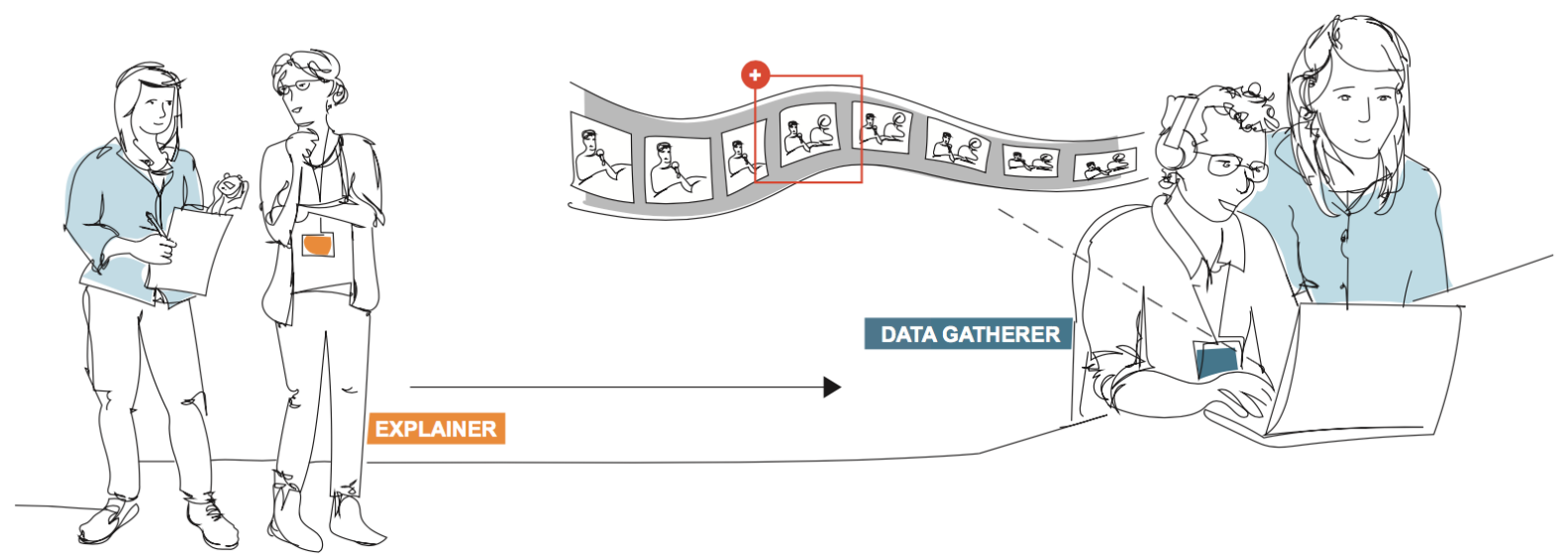

Figure 3: 'explainers' spotting interactional phenomena and inviting people to try 'data gathering'.

Visitors to the CR could gain hands-on experience with the process of recording, logging and collecting data for CA study. Several analysts worked as 'explainers': introducing the aims of the CR and involving visitors in the process of CA data collection (see Figure 3, left).

Analysts positioned near the Talkaoke table would approach visitors and explain the purpose of the exhibit, the overall principles and concepts of CA, and how CA methods were manifested within the CR exhibit. The explainers would use examples from Talkaoke to illustrate their brief introduction to $\mathrm{CA}$, and engage in visitor led discussions, where explanations could be tailored to the visitor's existing knowledge and experience. The explainer would then outline various opportunities for engagement with the exhibit, and offer that the visitor could stay and learn to spot conversational phenomena as they unfolded live around the Talkaoke table. Visitors were encouraged to track phenomena of interest by noting times of their observations so they could find and examine them later in the video recordings. Analysts could then direct visitors to the data gathering station where they could review their phenomena of interest via just-captured video. 'Data gatherers' (see Figure 3, right) were stationed at computers with access to the video stream from the Talkaoke table, and could work with members of the public to create video clips of a phenomenon by capturing footage from the live video, then adding them to an ever-growing 'collection' of similar instances.

This process gave visitors hands-on experience of handling video data and in making collections: the first step towards generalizing findings from single cases in CA research. Once a specific phenomenon of interest has been noticed and analyzed, conversation analysts tend to look out for similar instances in subsequent viewings (Sidnell, 2013). The analyst makes a collection, comprised of as many apparently related instances as possible (Schegloff, 1996). The analyst may also include 'boundary' cases that are not produced in precisely identical sequences, or which seem to result in different interactional outcomes (Schegloff, 1997). It is important to include instances that are potentially deviant, as they can provide information on what the central mechanism is. The analyst then compares all instances checking for regularities. For example, raising one's hand or opening one's mouth are two behaviors that could achieve the outcome of acquiring the microphone at Talkaoke. Visitors to the CR could contribute to collections by observing and noting new instances of the same behavior, or by searching through the recordings of the data alongside an analyst. This process of spotting and data gathering showed visitors how routine interactional behaviors can be, and how repeated use of the same behavior could achieve a predictable outcome. 


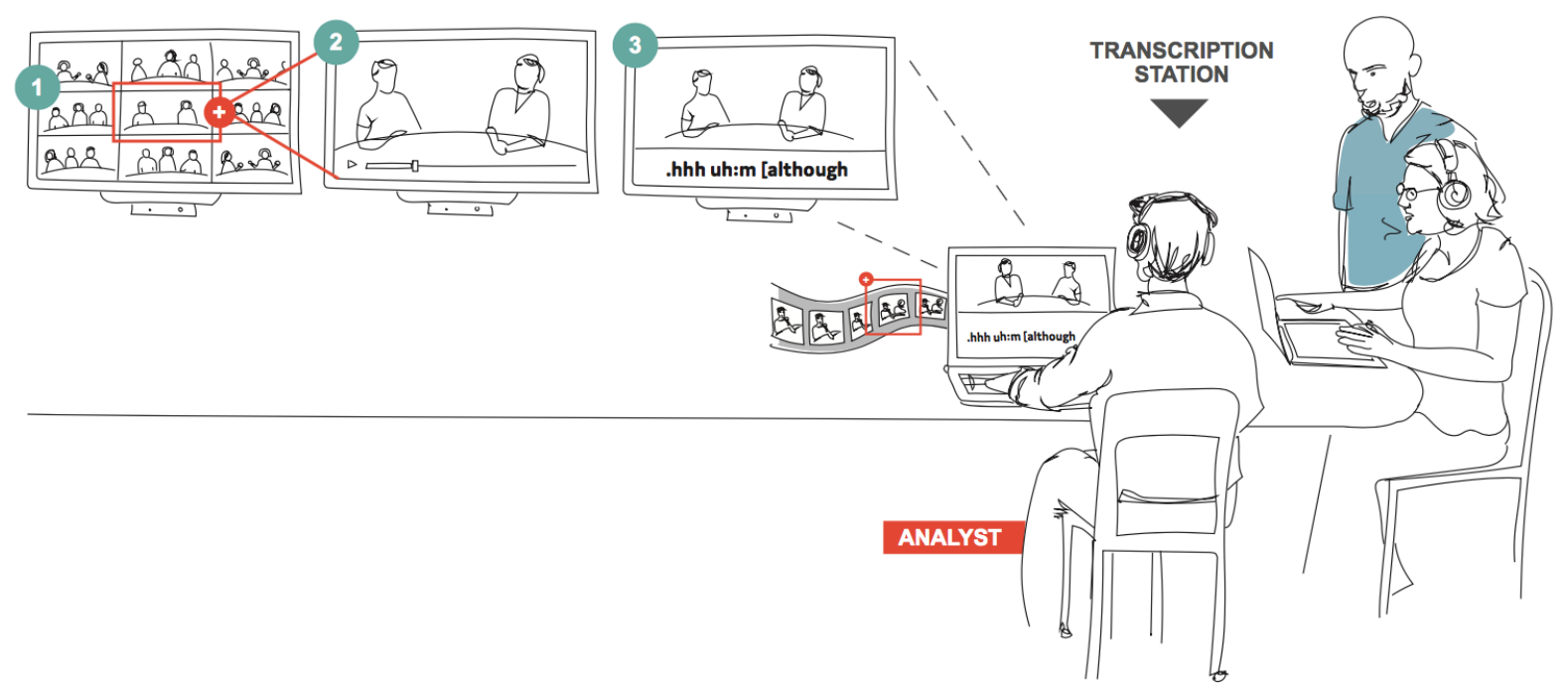

Figure 4: The transcribing station, where visitors could learn to transcribe and subtitle recordings.

Visitors could also learn to transcribe recordings, and then make their transcripts and clips visible to other passers-by on nearby video displays. The transcription station involved a transcriber working with their back to the visitors, making their laptop screen visible to all as they subtitled and annotated video clips. The transcriber would find an example of either the phenomenon of interest a visitor had previously identified and would then work with the visitor to transcribe the raw data using conversation analytic conventions, and explain the purpose of Jeffersonian transcripts as part of the analytical process. Three large video displays (see Figure 4) showed recently captured video clips and transcripts along with the surtitle: 'We are analyzing how people do $\mathrm{X}$ in the footage we've just recorded from Talkaoke' (where $\mathrm{X}$ is the current phenomenon of interest). A novel piece of interactive software was used to animate these displays ${ }^{9}$ and explain the analytic process: one screen (Figure 4.1) showed collections of phenomena recently recorded at the Talkaoke Table on a $3 \times 3$ grid of looping video excerpts. The next screen (Figure 4.2) showed one of those excerpts looping at full-screen, the third (Figure 4.2) showed the same excerpt subtitled with Jeffersonian symbols and highlights. This procedure highlighted the transition between the live event, the gathering of collections, the transcriber's laptop screen and the large displays overhead where talk has been processed into something that becomes recognizable as 'data'.

The CR's animation of a CA production line as it renders live conversation into transcribed data aimed to show that the ordinary and seemingly haphazard features of talk - what Goffman called, 'the greasy parts of speech' (1964, p.133) — can be analyzed systematically. This sought to address a long standing barrier to engaging in CA that Sacks (1984: 21) observed amongst social scientists who "view a society as a piece of machinery with relatively few orderly products". CA's methods, on the contrary, were designed to explore 'order at all points' in social life and human communications (Schegloff, 2005: 17-18), and the CR was designed to illustrate the regularities that can be discovered within a social order. The movement of visitors through the CR took them from participating in the conversation,

\footnotetext{
9 The software was built using 'Quartz Composer', a development tool for processing and rendering live graphical and audiovisual data. See https://developer.apple.com/library/content/documentation/GraphicsImaging/Conceptual/QuartzComposerUser Guide/qc_intro/qc_intro.html
} 
to spotting, gathering, and analyzing a highly detailed and annotated clip of interactional data. Instead of focusing on what the talk was ostensibly 'about', the goal of the CR was to involve visitors in discovering what a specific utterance, movement, or a short pause could achieve. The video loops of routine behaviours on the video screens reinforced this demonstration of 'order at all points' by showing how they tend to achieve their routine interactional outcomes. The transcription station also harnessed the familiarity of the sci-fi film cliché in which complicated visual displays are used to convey drama within otherwise dull, administrative processes. Here, however, this also served to highlight the relative importance of these minute and mundane features of interaction for CA's analytic method. Computer interfaces designed for use 'on stage' can be as useful for spectators as well as for their operators (Reeves et al. 2005, Spence 2016), and for the CR's, these displays highlighted a route through which passers-by, slowing down to look at Talkaoke and the big screens could become scientists, working on gathering, transcribing and analysing conversational data.

\section{Scientific results in public}

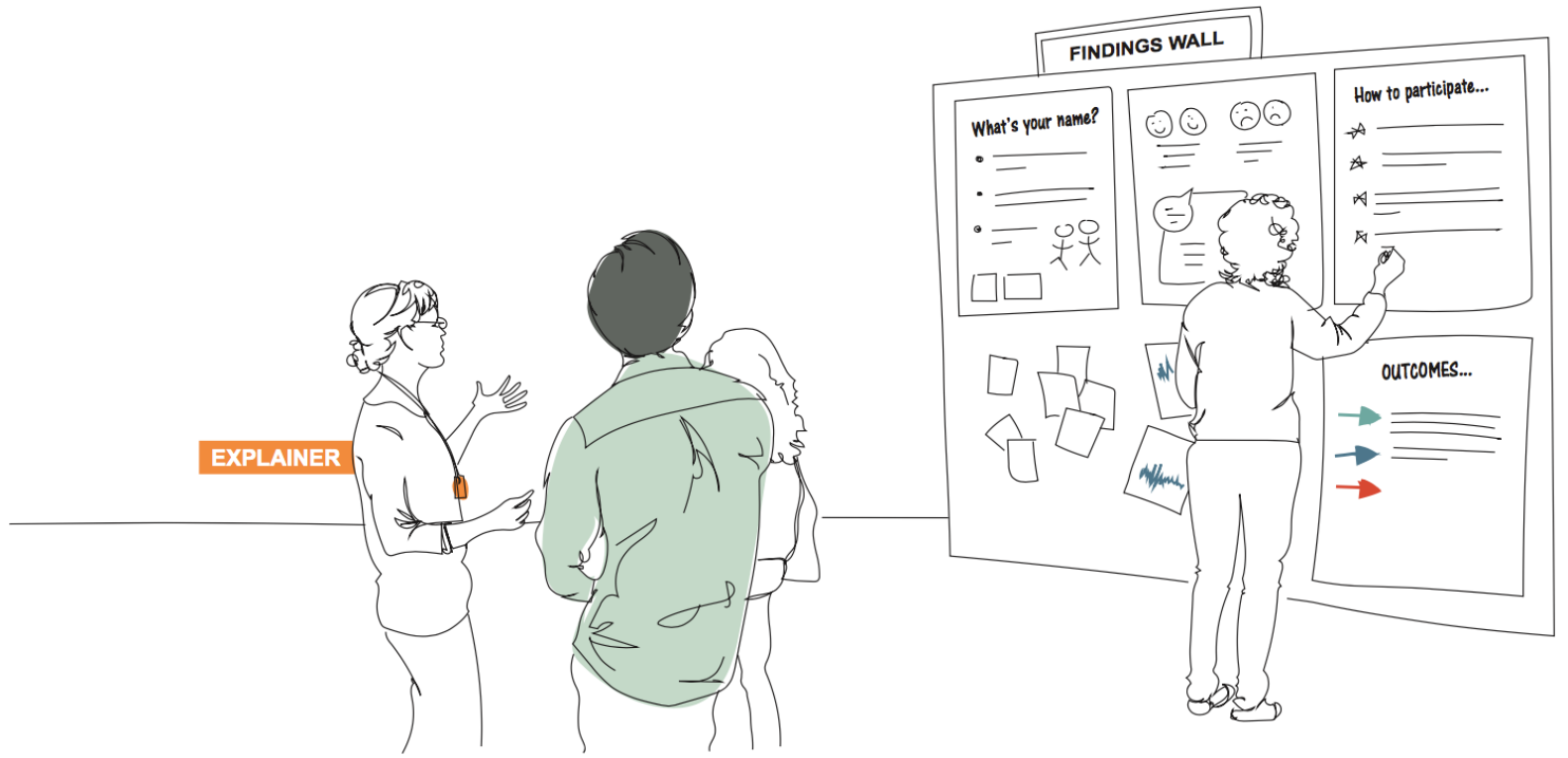

Figure 5: The findings wall, where analyses and results were written up and explained to visitors.

The production line of the CR's various activity stations ended at the 'findings wall' (see Figure 5), where ad-hoc results were 'published' on a whiteboard as props for discussion between explainers and visitors. These hastily drawn-up analytic insights formed the backdrop of the exhibit, providing a cumulative visual representation of the findings arising from Talkaoke. The wall functioned like the film cliché of the detective's wall of evidencewith transcripts sketches and diagrams connected by arrows to comic strip style illusrationsr. These annotations and visualisations of observed behaviors were useful for explaining the existing results of the CR to visitors, and informing them about how they could get involved. The findings wall was updated when new analytic insights were generated and the latest results were produced, providing an iterative space to present the empirical work of visitors. For visitors who only stopped to watch, or only participated in the Talkaoke, the findings wall provided easily recognizable insights into the structure of the Talkaoke going on nearby. 'Explainers' could walk visitors up to the wall, and show people findings relating to the interactions unfolding right in front of them. This approach to exposing science as a process rather than displaying scientific results as artefacts became the CR's most successful strategy. 


\section{The impact of public dialogue}

The success of public engagement in science may be hard to measure (Terama et al., 2016), however, one clear demonstration of the CR's effectiveness in engaging visitors in dialogue with CA as a science of talk was how their observations, video clips and transcripts could contribute to viable ongoing research. For example, two A-level students Basimah Malik and Ashleigh Morgan participated in 'spotting' at the CR, and helped collect some video clips. They later wrote a short report of their experience where they describe what they discovered.

'As we were walking past numerous stalls at New Scientist Live we were particularly intrigued by 'Talkaoke'. Tempted as we were to join in, we decided to watch before we threw ourselves in at the deep end. Whilst we were watching people sitting down and sharing their views at a circular table, a cognitive scientist explained the conversation analysis session that was going on. On that day they were observing how people obtained the microphone; some examples we saw included people raising a hand, making eye contact with the person in possession of the microphone and tapping the table. Not only this, but it was also interesting to see how people were unsuccessful in being passed the microphone. An example of this was a gentleman who was very persistently attempting to get the microphone by sticking his hand out and signalling. When he failed to grasp the attention of others, he awkwardly retreated, touching his glasses and nose. We have all experienced something similar, but it was fascinating to see how individuals react to the same circumstances. We were then given the opportunity to edit clips of some examples we had spotted. It was really interesting to see how people use their body language to communicate what they may be too apprehensive to say verbally.'

Alongside this account, we can examine a fragment of interaction first spotted and collected by Basimah and Ashleigh in situ, and build on their original findings. The students found that people use 'self-grooms' (that is, touch their face, hair, etc.) when obtaining the microphone. In a short fragment of video (see http://bit.ly/public_sci_talk_eg1), Basimah and Ashleigh noticed the way a boy (B) attempts to select himself as next speaker until he finally gets the microphone and takes a turn. In the transcript below, which is segmented into three parts, descriptions of B's bodily actions are inserted in double parentheses, with a caret $\left(^{\wedge}\right)$ marking the point that the described action occurs in the line above. B's multiple mic requests throughout Extract 1 exhibit the phenomenon that Basimah and Ashleigh describe in their report: where 'self-grooms' such as touching the nose, face or hair seem to occur when participants are working to get the mic. However, a closer look at this clip suggests that these kinds of self-grooms begin well before the prospective speaker formulates an explicit request for the microphone. In each case, B times his movements that indicate a mic request at moments that anticipate possible completion points (or 'transition relevance places'-TRPs) in the current speaker's turn. Extract 1 begins as a woman with blue hair (W) is coming to the end of a long explanation of how her experience of working in IT suggests computers are unlikely to take over the world. The host is ' $M$ '. For a key to the transcript, see Appendix A. 

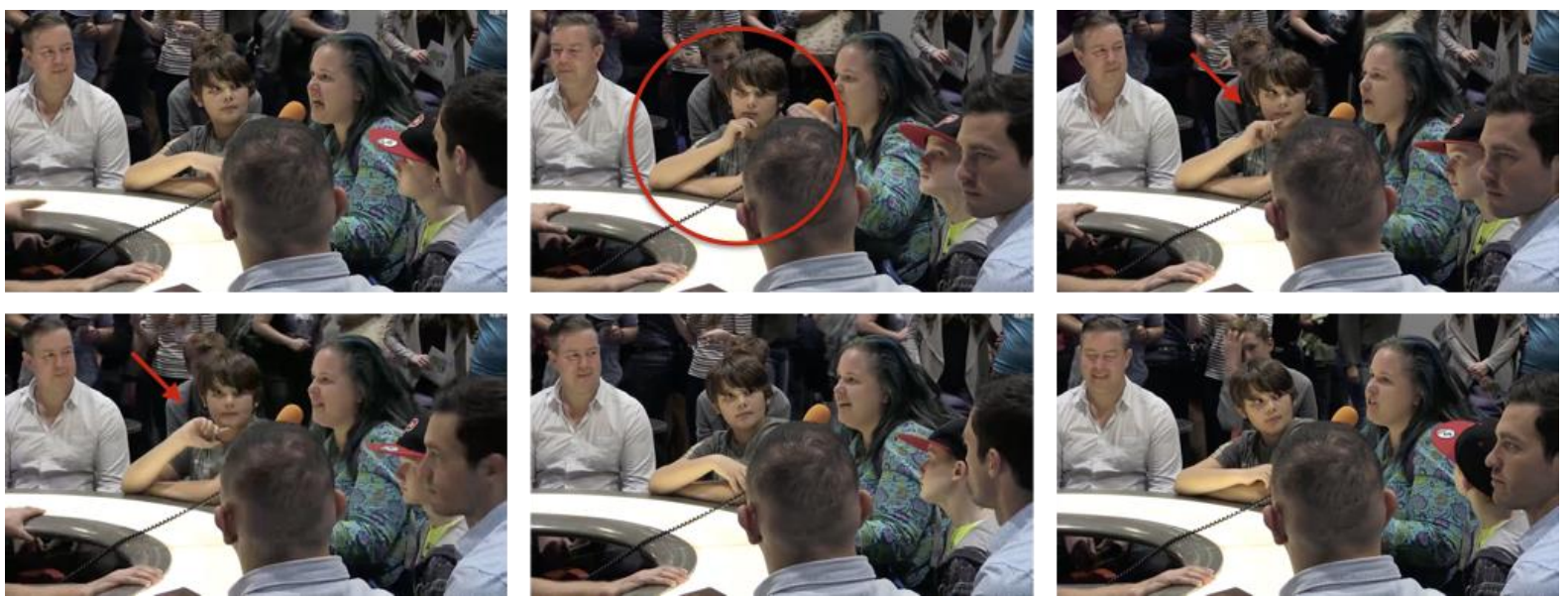

Figure 6: B begins to lift his hand to speak, then drops it as the current speaker continues.

\section{Extract 1: Clip 25}

(see video at http://bit.ly/public_sci_talk_eg1)

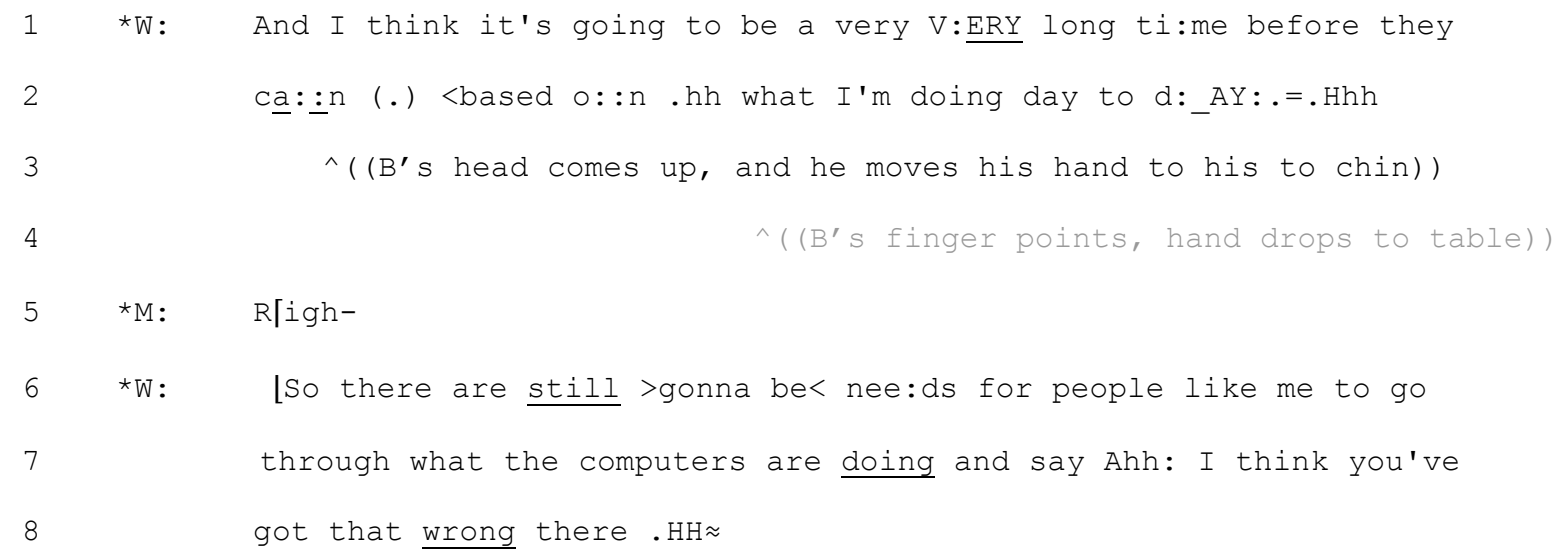

Although the move is subtle, at Line 2, B lifts his head and places his hand on his chin just as the current speaker (W) is approaching a point where her turn may possibly be complete (see Figure $6 \mathrm{~b}$ ). B then strokes his chin with the side of his right index finger and arranges his hand into a point and starts to lift it. However, when $\mathrm{W}$ then rushes to extend her possiblycomplete turn - marked by a less-than sign $(<)$ — the TRP passes, W continues to speak, and $\mathrm{B}$ drops his hand to the table (see Figure 6e). This action alone cannot be analysed as a request for the microphone as such, but B's subtle arm and hand movements can be treated as preparatory phase for a later request since he then goes on to request the mic more explicitly. 

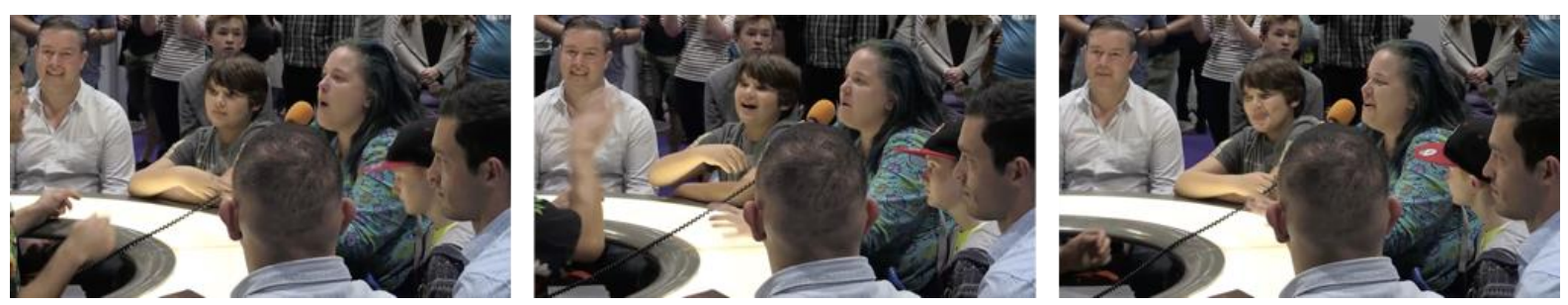

Figure 7: B lifts his hand to speak, then drops it as current speaker W continues again.

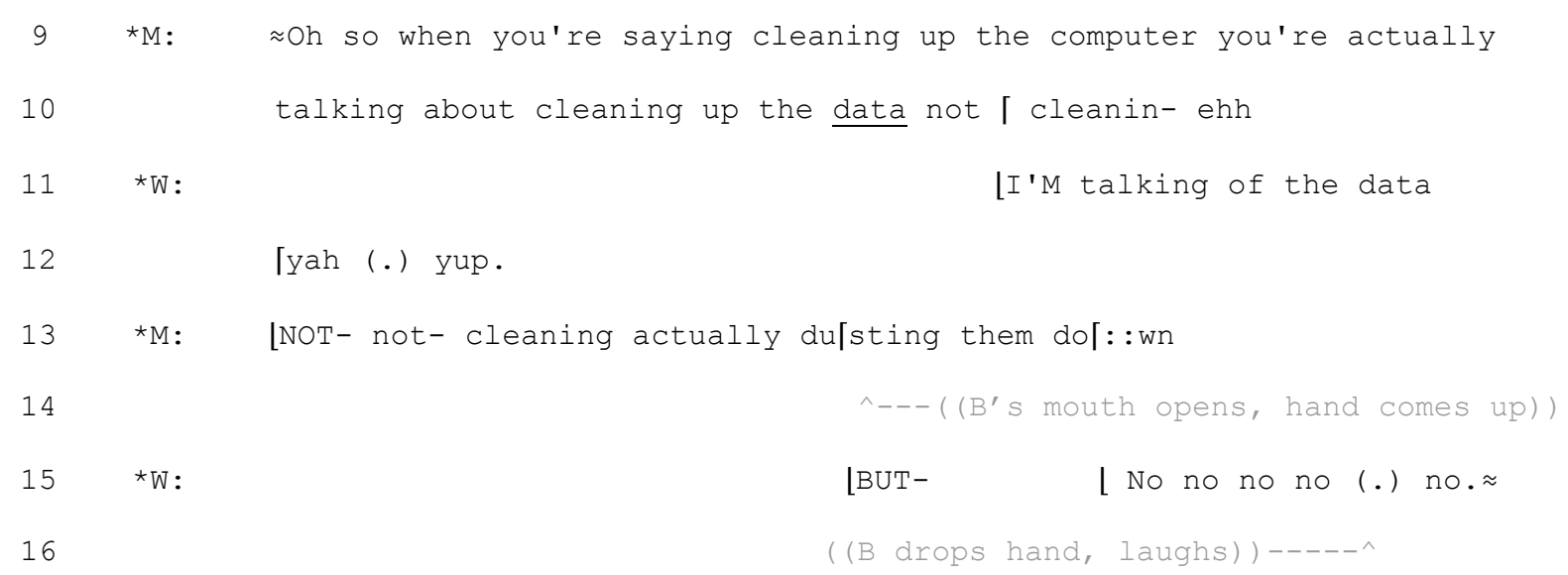

B's next move towards requesting the mic occurs at Line 14, at the next TRP when the host (M) responds to W's possibly-complete turn. Here B raises his hand, holding his mouth open, ready to speak (see Figure 7b). However, W and M take a series of closely latched turns, (M, as the host, can speak into his head-mounted microphone without moving the handheld mic) and B then joins their laughter then drops his hand back to the table (see Figure 7c).
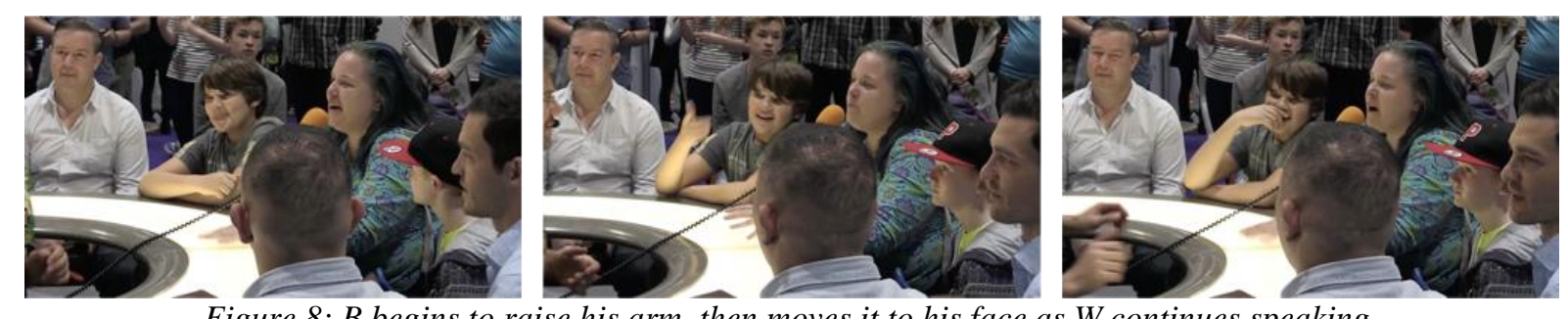

Figure 8: B begins to raise his arm, then moves it to his face as $W$ continues speaking.

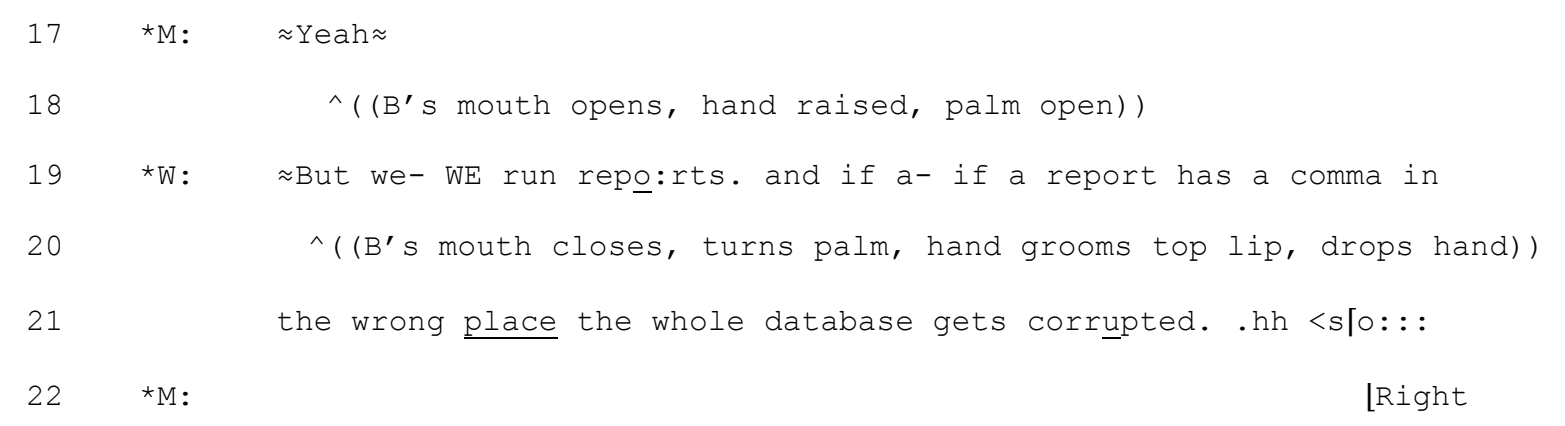


This pattern of mic-requesting and self-grooming is repeated for a third time at Lines 19-21 when $\mathrm{M}$ responds to W's possibly-complete turn and B once more opens his mouth and raises his hand (see Figure 8b). However, M produces only a minimal 'continuer' 'Yeah' (Line 17) without moving the mic, giving $\mathrm{W}$ the opportunity to take the next turn. B pivots his request into a self-groom, moving his hand to his mouth as W continues to speak (see Figure 8c).
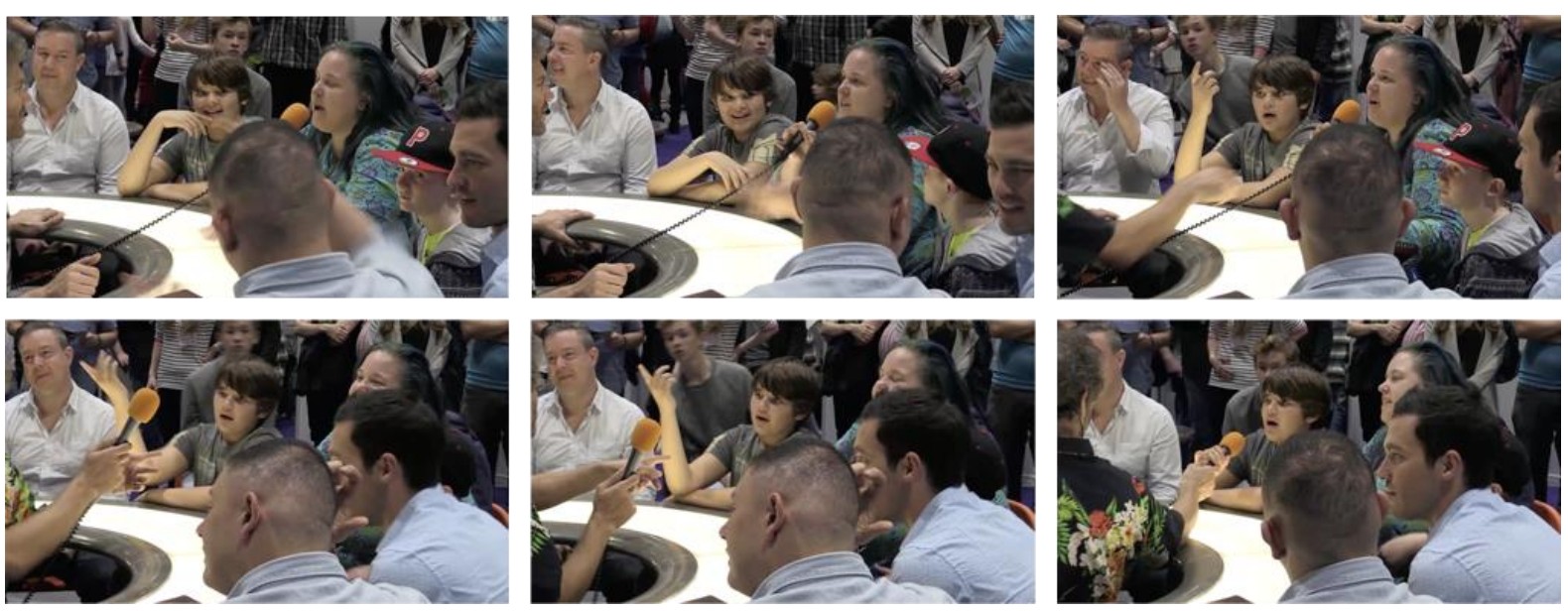

Figure 9: B finally gets the mic, keeping his arm raised, pointing and pulsing it upward as W finishes her turn.

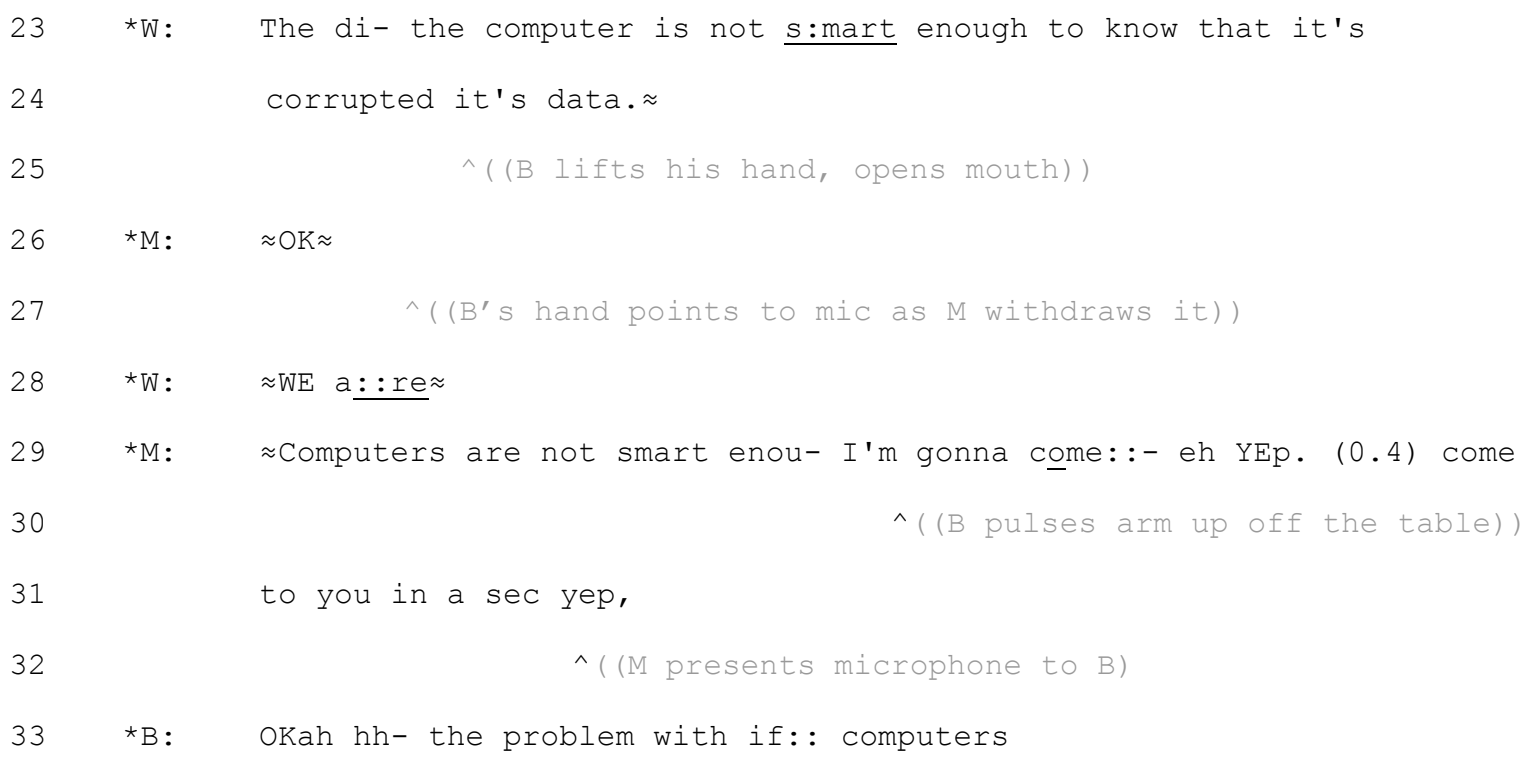

The phenomenon spotted by Basimah and Ashleigh formed the basis of a collection of similar 'pivots' of a bid for the mic into a groom. ${ }^{10}$ Even this brief analysis suggests that a publiclyinitiated collection can provide a viable basis for further CA study, and that their finding departs from popular science claims about the ostensibly flirtatious 'meaning' of self-grooms (Koeppel, Montagne-Miller, O'Hair et al. 1993). Visitors' participation in Talkaoke and the CR's analytic production line was both explanatory and constitutive of how interaction shaped the $\mathrm{CR}$ as a situation itself. The $\mathrm{CR}$ used this reflexive approach to achieve its central aim-to engage visitors in doing CA, testing its core materials and methods for themselves.

\footnotetext{
10 This phenomenon may be one specific variety of a common set of practices for pivoting actions such as requests into self-grooms, or to otherwise delay or defer an action (Goodwin, 1986; Raymond \& Lerner, 2017).
} 


\section{Conclusion}

Conversation analysts, like many academics, have not typically put themselves in the public spotlight to talk about, much less demonstrate, their work. The (often hierarchical) distinction between 'applied' and 'pure' science holds in CA as much as anywhere else (see Antaki, 2011) and this can be off-putting for academics. We know that the translation of academic work for non-academic audiences can result in the 'dumbing down' or complete misrepresentation of the original research, in pursuit of a soundbite or support for a particular political stance (e.g., Hansen, 2016). This can put academics off engaging with the public via the media or other forums. Despite these hurdles, over the last five years conversation analysis has seen increasing interest from non-academic audiences, which has resulted in a strong response from the public, as ordinary members of the public and as professionals in healthcare, legal, commercial, political, and other occupations. This has led to numerous user-led and user-funded projects as the world wakes up to the fact that CA exists, and to its usefulness in communication training, guidance and assessment. Starting from an unlikely appearance of a conversation analyst on a BBC Radio 4 show called 'The Life Scientific' (Buckley, 2013), which documents the research biographies of internationally acclaimed scientists, suddenly an audience wanted to know more about CA. Conversation analysts have delivered, for example, TED lectures, won WIRED innovation awards, been invited to give Royal Institution lectures, Wellcome Trust public platforms, commercial organizations, 'after dinner' speaking slots at government departments, and, as documented in this paper, New Scientist Live. What ties all these public engagement events together is the ready categorization (by those doing the inviting) of CA as a science. Each of these presentations proliferates yet further interest as people demand to know more about conversation analysis. These developments indicate that the time has come for a public science of talk, and that if CA can achieve this level of public interest, many more empirical approaches to talk can too.

Evidence of 'impact' and the success of public engagement comes at many levels, from, for example, doctors, companies or government agencies approaching conversation analysts to co-design research, to social media comments and 'altmetrics' (Priem, Taraborelli, Groth \& Neylon, 2011). These engagements all constitute some form of public dialogue. For example, when people tweet about the fragments of conversation shown in a talk, or make comments on a lecture that is hosted on YouTube, their understanding and interest is evident. However, as a measure of success in engaging the public in dialogue, these reflect the impact of communicating scientific results, and tend to focus on the outcomes and implications of research narratives that seem most newsworthy. This focus on results and newsworthy narratives does little to differentiate one process of discovery from another. It does not provide people with the means to understand the validity of the methods underlying the findings, nor the relevance of those methods to the domain being studied. Nor does it suggest how to improve these kinds of public dialogues because it takes its 'measures' from a position outside the situation itself. For example, imagine a patient calling their GP to make an appointment. If they are dissatisfied, they can record their dissatisfaction on the national GP Patient Survey in England on a scale of 1-10. But when the surgery examines this evaluation, what should they do if scores are low? Practitioners struggle to identify and action changes based on feedback alone; knowing what to improve can be based on "hunches" or "best guesses" (Goldstein, Cialdini and Griskevicius, 2008). They can also be stereotypical ("smile when you answer the phone!") or empirically wrong ("use the patient's name to build rapport"). The power of conversation analysis is in demonstrating what practitioners do that is effective or ineffective from within their interactions with patients; in the moments of silence, repetitions, interruptions, and the premature closings that constitute their work. 
The conversational rollercoaster, by contrast, showed how the impact of public engagement and dialogue with science can be evaluated in relation to the practices of that scientific field. Visitors to the CR were not asked to complete feedback forms, online surveys or other traditional event evaluations. Instead, evidence of impact was gathered as part of the event itself, as an integral feature of how it worked. The fact that visitors to the CR could make observations, which subsequently provided the starting point for further analysis provides a suitably endogenous measure of the exhibit's effectiveness. The CR's production line of systematic observation and discovery engaged visitors in working alongside scientists doing CA, and through their involvement, it demonstrated CA's public ethos, data and methods. It also provided analysts with opportunities to improve their work practices and to see precisely how and where the various stages of the production line broke down: where visitors would lose interest, or begin speculating and theorizing rather than focusing on the data at hand. Given the lack of public familiarity or established methods for science engagement in CA, it may seem surprising that people are so willing to get involved in a science of talk. However, this should encourage us to find ways to engage people in the study of language, dialogue and interaction. Since we know how to talk, but lack the methods to analyze it scientifically, talk itself may be an especially useful empirical material both for engaging people in a public dialogue about science, but then also for engaging them in the study of dialogue as science.

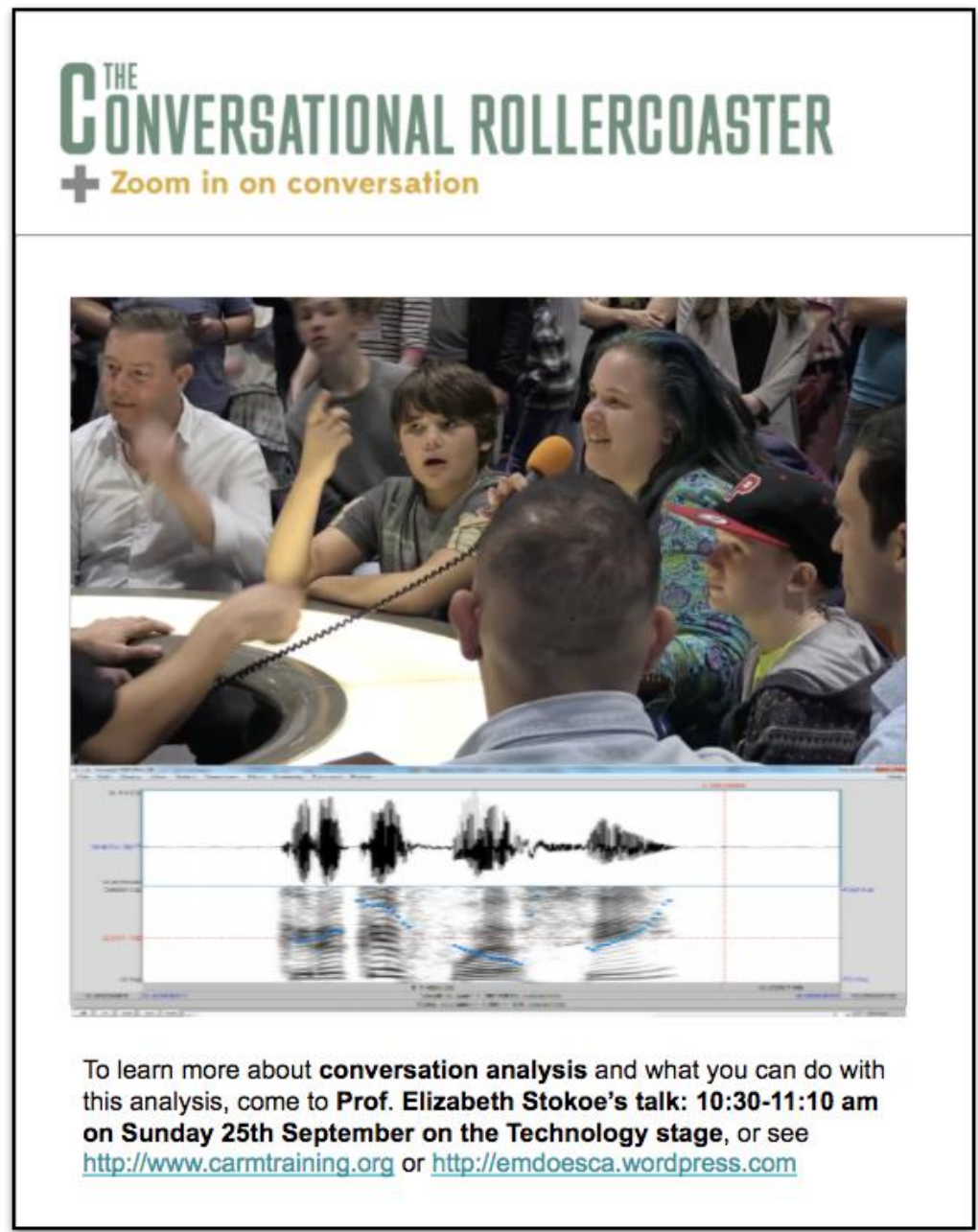

Figure 10: An example of the 'snapshot' handed to visitors as they got up to leave the Talkaoke table. 


\section{Acknowledgements}

The authors would like to thank the team from A Dozen Eggs (http://www.adozeneggs.co.uk) for the illustrations in this paper and for the Conversational Rollercoaster itself, the Talkaoke team Mikey Weinkove, Rick Sleiman and Rohan Mehra, Matthew Jarvis for the visual display software and Ella Rice from QMUL Outreach for her support with the New Scientist Live event. We would also like to thank our colleagues who participated in and helped shape the Converastional Rollercoaster: Charles Antaki, Rein Skiveland, Jessica Robles, Veronica Gonzalez, Joe Ford, Bogdana Huma, Ann Doehring, Marc Alexander, John Rae, Samantha Duffy, Alexandra Kent, Charlotte Albury, Toby Harris, Betül Aksu and Vanessa Pope.

The authors would also like to acknowledge funding for the Conversational Rollercoaster from Queen Mary University of London and Loughborough University, and to thank the University of York, Keele University, the University of Oxford and Roehampton University for supporting the participation of their staff and students. We also acknowledge our funding from the Engineering and Physical Sciences Research Council (EPSRC) through the Media and Arts Technology Programme, a Research Councils UK Centre for Doctoral Training (EP/G03723X/1), and support for Edward J. B. Holmes' participation by Economic and Social Research Council doctoral award conferred by the Department of Sociology at the University of York. Dr. Hofstetter's participation was funded by Alex Stein, partner. 


\section{Bibliography}

Albert, S. (2014). The data session. Available at: http://saulalbert.net/blog/the-data-session/. Accessed: 16/12/2016.

Antaki, C. (Ed.). (2011). Applied Conversation Analysis: Intervention and Change in Institutional Talk. Basingstoke: Palgrave Macmillan.

Antaki, C., Biazzi, M., Nissen, A., \& Wagner, J. (2008) Managing moral accountability in scholarly talk: The case of a Conversation Analysis data session, Text and Talk, 28(1), 1-30.

Atkinson, M. (1984). Our Masters' Voices: The Language and Body Language of Politics. London: Routledge.

Atkinson Maxwell, J. (2010[1985]). Claptrap: how to win a standing ovation [Video file]. Retrieved from http://maxatkinson.blogspot.com/2010/02/claptrap-movie-revisited.html

Bourdieu, P. (1988). Homo Academicus. Translated by: P. Collier. Stanford: Stanford University Press.

Buckley, A. (Producer). (2013, June 25). The Life Scientific: Elizabeth Stokoe [Radio show]. Retrieved from http://www.bbc.co.uk/programmes/b02ykg4w

Bushnell, C. (2012). Talking the talk: The interactional construction of community and identity at conversation analytic data sessions in Japan. Human Studies, 35(4), 583-605.

Chomsky (1964). Aspects of the Theory of Syntax. MIT Press, Cambridge MA.

Clayman, S. (2002). Sequence and Solidarity. In E. J. Lawler., \& S. R. Thye. (Eds.). Advances in Group Processes: Group Cohesion, Trust and Solidarity. Oxford: Elsevier Science, pp. 229-53.

Coser, L. A. (1975). Presidential address: Two methods in search of a substance. American Sociological Review, 40(6), 691-700.

Curl, T. S., \& Drew, P. (2008). Contingency and action: A comparison of two forms of requesting. Research on Language and Social Interaction, 41(2), 129-153.

Drew, P. (2009). "Quit talking while I'm interrupting": a comparison between positions of overlap onset in conversation, in Haakana, M.; Laakso, M. \& Lindstrom, J. (Eds.) Talk in Interaction: Comparative Dimensions. Finnish Literature Society, Helsinki

Goffman, E. (1963). Behavior in Public Places. The Free Press: New York.

Goldstein NJ, Cialdini RB, Griskevicius V. (2008). A room with a viewpoint: Using social norms to motivate environmental conservation in hotels. Journal of Consumer Research. 35(3): 472-482. 
Goodwin, C. (1981). Conversational Organization: Interaction between Speakers and Hearers. New York: Academic Press, Inc.

Goodwin C (1986) Gestures as a resource for the organization of mutual orientation. Semiotica 62(1-2): 29-49.

Hansen, A. (2016). The changing uses of accuracy in science communication. Public Understanding of Science. DOI: 10.1177/0963662516636303

Harris, J., Theobald, M., Danby, S., Reynolds, E., \& Rintel, S. (2012). "What's going on here?" The pedagogy of a data analysis session. In L. Alison., \& S. Danby. (Eds.). Reshaping Doctoral Education: International Approaches and Pedagogies. London: Routledge, pp. 8396.

Heap, J. L. (1990). Applied Ethnomethodology: Looking for the Local Rationality of Reading Activities Human Studies, Springer, 13, 39-72

Hepburn, A., \& Bolden, G. B. (2013). The Conversation Analytic Approach to Transcription. In J. Sidnell., \& T. Stivers. (Eds.). The Handbook of Conversation Analysis. Oxford: Blackwell, pp. 57-76.

Heritage, J. (2003). Presenting Emanuel Schegloff. In C. L. Prevignano., \& P. J. Thibault. (Eds.). Discussing Conversation Analysis: The work of Emanuel A. Schegloff. John Benjamins: Amsterdam, pp. 1-10.

Heritage, J. (2008). Conversation analysis as social theory. In B. Turner. (Ed.). The New Blackwell Companion to Social Theory. Oxford: Blackwell, pp. 300-320.

Heritage, J. (2012). The epistemic engine: Sequence organization and territories of knowledge. Research on Language and Social Interaction, 45(1), 30-52.

Heritage, J., Robinson, J. D., Elliott, M. N., Beckett, M., \& Wilkes, M. (2007). Reducing patients' unmet concerns in primary care: the difference one word can make. Journal of General Internal Medicine, 22(10), 1429-1433.

Heritage, J., \& Greatbatch, D. (1986). Generating applause: A study of rhetoric and response at party political conferences. American Journal of Sociology, 92(1), 110-157.

Holmes, E. J. B. (in preparation). Interaction, Identity \& Social Class. (Unpublished Doctoral Thesis). University of York, York.

International Phonetic Association (1999). Handbook of the International Phonetic Association Cambridge University Pr., Cambridge.

Jefferson, G. (1988). On the sequential organization of troubles-talk in ordinary conversation. Social Problems, 35(4), 418-441.

Jefferson, G. (2004). Glossary of Transcript Symbols with an Introduction. In G. Lerner. (Ed.). Conversation Analysis: Studies from the First Generation. Amsterdam: John Benjamins. pp. 13-31. 
Kitzinger, C. (1998). Inaccuracies in quoting from data transcripts: or inaccuracy in quotations from data transcripts. Discourse \& Society, 9(1), 136-143.

Kitzinger, C. (2000). Doing feminist conversation analysis. Feminism \& Psychology, 10(2), 163-193.

Kitzinger, C. (2005). "Speaking as a Heterosexual": (How) Does Sexuality Matter for Talkin-Interaction?. Research on Language and Social Interaction, 38(3), 221-265.

Lynch, M., \& Bogen, D. (1994). Harvey Sacks's primitive natural science. Theory, Culture \& Society, 11(4), 65-104.

Lerner, G. H. \& Raymond, G. (2017). On the practical re-intentionalization of body behavior. In Raymond, G, Lerner, G and Heritage J (Eds.), Enabling Human Conduct: Studies of talkin-interaction in honor of Emanuel A. Schegloff, John Benjamins Publishing Company, Amsterdam, 299-313.

Maynard, D. W., Schaeffer, N. C., \& Freese, J. (2011). In C. Antaki. (Eds.). Applied Conversation Analysis: Intervention and Change in Institutional Talk. Basingstoke: Palgrave Macmillan, pp. 54-74.

Mills, C. W. (1959). The Sociological Imagination. Oxford: Oxford University Press.

Mondada, Lorenza, 2014. Conventions for Multimodal Transcription.

https://franz.unibas.ch/fileadmin/franz/user_upload/redaktion/Mondada_conv_multimodality. pdf (Accessed 13.03.17).

J. Priem, D. Taraborelli, P. Groth, C. Neylon (2010), Altmetrics: A manifesto, 26 October 2010. Retrieved from http://altmetrics.org/manifesto

Ranehill, E.; Dreber, A.; Johannesson, M.; Leiberg, S.; Sul, S. \& Weber, R. A. (2015). Assessing the Robustness of Power Posing Psychological Science, SAGE Publications, 26, 653-656

Reeves, S., Benford, S., O'Malley, C., \& Fraser, M. (2005). Designing the spectator experience (pp. 741-750). Proceedings of the SIGCHI Conference on Human Factors in Computing Systems.

Richards, K., \& Seedhouse, P. (Eds.). (2005). Applying Conversation Analysis. Palgrave Macmillan, Basingstoke.

Sacks, H. (1967). The search for help: No one to turn to. (Unpublished doctoral dissertation). University of California, Berkeley.

Sacks, H. (1992 [1964-1965]). An impromptu survey of the literature. In G. Jefferson., \& E. A. Schegloff. (1992). (Eds.). Lectures on Conversation: Volume I \& Volume II. Oxford: Blackwell Publishing, pp. 26-31. 
Sacks, H. (1992 [1966]). Various methodological issues. In G. Jefferson., \& E. A. Schegloff. (1992). (Eds.). Lectures on Conversation: Volume I \& Volume II. Oxford: Blackwell Publishing, pp. 467-472.

Sacks, H. (1992 [1967]). General Introduction. In G. Jefferson., \& E. A. Schegloff. (1992). (Eds.). Lectures on Conversation: Volume I \& Volume II. Oxford: Blackwell Publishing, pp. 619-623.

Schegloff, E. A. (1984). On some gestures' relation to talk. In M. J. Atkinson., \& J. Heritage. (Eds.). Structures of Social Action: Studies in Conversation Analysis. Cambridge: Cambridge University Press, pp. 266-296.

Schegloff, E. A. (1987a). Analyzing single episodes of interaction: An exercise in conversation analysis. Social Psychology Quarterly, 50(2), 101-114.

Schegloff, E. A. (1987b). Between Micro and Macro Contexts and Other Connections. In J. Alexander., R. Munch., B. Giesen., \& N. Smelser. (Eds.). The Micro-macro link. Berkeley: University of California Press, pp. 207-234

Schegloff, E. (1992). Introduction. In G. Jefferson., \& E. A. Schegloff. (Eds.). Lectures on Conversation: Volume I \& Volume II. Oxford: Blackwell Publishing, pp. ix-lxii.

Schegloff, E. A. (1996). Confirming allusions: Toward an empirical account of action. American Journal of Sociology, 102(1), 161-216.

Schegloff, E. A. (1997). Whose text? Whose context?. Discourse \& Society, 8(2), 165-187.

Schegloff, E. A. (1999). Naivete vs sophistication or discipline vs self-indulgence: A rejoinder to Billig. Discourse \& Society, 10(4), 577-582.

Schegloff, E. A. (2005). Whistling in the dark: Notes from the other side of liminality. Texas Linguistic Forum, 48, 17-30.

Schegloff, E. A. (2006). Interaction: The infrastructure for social institutions, the natural ecological niche for language, and the arena in which culture is enacted. In N. J. Enfield., \& S. C. Levinson. (Eds.). Roots of Human Sociality: Culture, Cognition, and Human Interaction. Oxford: Berg, pp. 70-96.

Schegloff, E. A., Koshik, I., Jacoby, S., \& Olsher, D. (2002). Conversation Analysis and Applied Linguistics. Annual Review of Applied Linguistics, 22, 3-31.

Schenkein, J. (1978). Identity negotiations in conversation. In J. Schenkein. (Ed.). Studies in the Organization of Conversational Interaction, New York: Academic Press, pp. 57-78.

Schütz, A. (1962). Phenomenology and the social sciences. In M. Natanson (Ed.), Collected Papers I: The Problem of Social Reality (Vol. 11, pp. 118-139). Springer Netherlands. doi:10.1007/978-94-010-2851-6_5

Sikveland, R., Stokoe, E. \& Symonds, J. (2016). Patient burden during appointment-making telephone calls to GP practices. Patient Education and Counseling, 99, 1310-1318 
Speer, S. A., \& Stokoe, E. (Eds.). (2011). Conversation and Gender. Cambridge: Cambridge University Press.

Spence, J. (2016). Performative Experience Design. Springer Series on Cultural Computing. Cham: Springer International Publishing. http://doi.org/10.1007/978-3-319-28395-1

Stokoe, E. (2011). Simulated Interaction and Communication Skills Training: The 'Conversation-Analytic Role-Play Method' in Antakie, C. (Ed.) Applied Conversation Analysis, Palgrave Macmillan UK, 119-139

Stokoe, E. (2013). Applying findings and creating impact from conversation analytic studies of gender and communication. Economic and Industrial Democracy, 34 (3), DOI: $10.1177 / 0143831 X 13489043$.

Stokoe, E. (2014). The Conversation Analytic Role-play Method (CARM): A method for training communication skills as an alternative to simulated role-play. Research on Language and Social Interaction, 47(3), 255-265.

Terämä, E.; Smallman, M.; Lock, S. J.; Johnson, C. \& Austwick, M. Z. (2016). Beyond Academia - Interrogating Research Impact in the Research Excellence Framework PLOS ONE, Public Library of Science (PLoS), 11 doi: 10.1371/journal.pone.0168533

Turner, S. (2001). Throwing out the tacit rule book: Learning and practices, in R.Schatzki, T.; KnorrCetina, K. \& von Savigny, E. (Eds.) The practice turn in contemporary theory, Routledge, London, 120-30.

Van Noorden, R.; Maher, B.; Nuzzo, R. (2014). The top 100 papers Nature, Macmillan Publishers Ltd., London, England, 514, 550-553

Whitehead, K. A. (2009). "Categorizing the categorizer": The management of racial common sense in interaction. Social Psychology Quarterly, 72(4), 325-342.

Wilkinson, S. (2011). Improving Ethnic Monitoring on a Telephone Helpline. In C. Antaki. (Eds.). Applied Conversation Analysis: Intervention and Change in Institutional Talk. Basingstoke: Palgrave Macmillan, pp. 75-97. 